\title{
Effects of Speaking Rate and Sonority on Voicing Duration in Russian Obstruents
}

\author{
Vladimir Kulikov \\ Department of English Literature \& Linguistics (DELL) \\ Qatar University \\ Doha, Qatar
}

\begin{abstract}
Research has found that temporal cues to obstruent voicing in aspirating languages, e.g. VOT or closure voicing, are affected by context, e.g. speaking rate or phonetic environment. However, little is known about effects of phonetic context on acoustical properties of word-medial obstruents in true voice languages. The present study investigates changes in duration of glottal pulses in Russian word-medial obstruents. The data come from 14 Russian speakers, who pronounced phrases with 2165 voiced and voiceless obstruents before segments with low and high sonority in the slow and fast speaking rate conditions. The findings provide empirical evidence that duration of glottal pulsing in voiced obstruents increases in response to sonority of adjacent segment and at slow speaking rate. The findings reveal that the maximum increase $(57 \mathrm{~ms})$ was found in prevocalic position at slow rate, suggesting sonority and speaking rate may feed one another to enhance glottal pulsing in voiced obstruents.
\end{abstract}

Keywords: laryngeal contrast, obstruent voicing, sonority, speaking rate, Russian

\section{Introduction}

Contextual variation within phonological categories and processes is a classic problem in phonological theory. It has been a standard assumption that phonological categories are discrete and phonological processes are categorical (e.g. Chomsky \& Halle, 1968). Variation and gradience, in contrast, are properties of phonetic processes (Cole, Linebaugh, Munson \& McMurray, 2010; Gow, 2001;Gow \&McMurray,2007; Ohala, 1996; Pierrehumbert, 2003).In recent years, there has been an increasing interest in mechanisms that regulate the interface between rule-governed phonology and gradient and variable phonetics (e.g. Smolensky, Goldrick \& Mathis, 2014).

Voicing is one of the phonological contrasts that exhibits gradience and contextual variation. Studies of voice onset time (VOT)(Lisker\&Abramson,1964), one of the most salient temporal cues to voicing in word-initial stops, reveal that phonetic gradience often emerges as variability in cues due to phonetic context (Klatt, 1975; Docherty, 1992; van Alphen \& Smits, 2004) or speaking rate (Allen \& Miller, 1999; Kessinger \& Blumstein, 1997; Magloire \& Green, 1999; among others).

Context-dependent variation in VOT is typically realized as differences in VOT in response to sonority of phonetic context. Researchers have reported that more sonorous prevocalic position provides the environment for longer glottal pulsing (voicing), whereas less sonorous presonorant position suppresses duration of voicing (Klatt, 1975;van Alphen \& Smits, 2004; Kulikov, 2012). As a result, prevocalic voiced stops tend to have longer duration of prevoicing (lead voice with negative VOT) than voiced stops produced before sonorant consonants. VOT in voiceless stops is also sensitive to phonetic context. Aspiration (long lag VOT) in prevocalic voiceless aspirated stops is reported to be shorter than aspiration in presonorant voiceless aspirated stops (Klatt, 1975). Another source of variation intemporal cues to voicing, including VOT, is speaking rate. Cross-linguistic studies of VOT report that in word-initial stops VOT changes in response to manipulation with speaking rate. Talkers tend to produce longer aspiration and prevoicing in slower speech in a variety of languages (e.g. Allen \& Miller, 1999; Kessinger \& Blumstein, 1997; Magloire \& Green, 1999;:Smiljanić \& Bradlow, 2008).

Intriguingly, the two contextual factors, speaking rate and sonority of phonetic context, reveal striking similarities in the way they affect VOT. Slow speaking rate and phonetic context with higher sonority (vowels) lead to an increase in duration of glottal pulsing in an obstruent, while fast rate and phonetic context with lower sonority (consonants) create the opposite effect. No study, however, has investigated combined contextual effects of speaking rate and phonetic environment.

Although contrasting voicing in stops (and obstruents in general) pertains as a discrete category to all prosodic positions, most empirical studies investigated the voicing contrast in word-initial stops. Far too little attention has been paid to contextual details in implementation of the voicing contrast in word-medial stops. 
A phonetic cue that is typically used to determine the laryngeal category of a stop in this prosodic position is duration of glottal pulsing during stop closure, or closure voicing (Lisker \& Abramson, 1967). Both cues - VOT and closure voicing - reflect the same fundamental relation between the timings of oral constriction and vibration of the vocal folds. Prevoicing (negative VOT) in word-initial voiced stops and voicing during closure in word-medial stops result from overlap between production of the glottal pulses and the oral closure gesture, when glottal pulsing precedes release. Positive VOT in word-initial voiceless stops and voiceless closure in voiceless word-medial stops are, in contrast, the result of the sequence of the two gestures when glottal pulsing follows stop release (Lisker \& Abramson, 1964).This study seeks to examine the role of contextual variation in obstruent's in Russian, a true voice language. It aims to examine magnitude of the two contextual effects, - speaking rate and sonority of phonetic environment, - on duration of glottal pulses in word-medial stops and fricatives.

\section{Theoretical Background: Obstruent Voicing and Context}

VOT and closure voicing, as temporal cues to voicing, are sensitive to contextual changes that involve timing of articulatory gestures. Cross-linguistic studies have revealed a fundamental relationship between VOT in word-initial stops and speaking rate. Allen and Miller (1999) demonstrated that VOT in English voiceless aspirated stops lengthened in slow speech. They also found that the response to rate in VOT was asymmetrical. VOT increased in slower speech only in aspirated stops, but VOT in unaspirated stop did not change. Kessinger and Blumstein's (1997) analysis of VOT in English, French and Thai revealed asymmetrical changes in all these languages. VOT increased in slower speech in aspirated stops in English and Thai. In a similar fashion, prevoicing in voiced stops also increased in French and Thai as speech slowed. However, short-lag VOT in voiceless unaspirated stops in English and French did not change at slow rate.

Several studies have explored factors that were believed to influence the asymmetry. Kessinger and Blumstein (1997) proposed an explanation that the effect of rate may be a result of the strategy of the speakers to maintain the contrast by holding one category constant. Later, the studies of rate effects on VOT in a variety of languages have revealed that the category affected by rate is typically active in the phonology of a language. Beckman,Helgason, McMurray and Ringen (2011)argued that effects of speaking rate are found in the acoustic cues (e.g. VOT) that correlate with the active feature(s) underlying a phonological contrast. For example, in true voice languages, which use the feature [voice], it is prevoicing that becomes longer in slower speaking rates. Likewise, duration of aspiration also increases in slower speech in aspirating languages, which use the feature [spread glottis].

In addition to speaking rate effects, VOT has been shown to change in different phonetic contexts. As reported in literature, VOT varies as a function of sonority of the segment that follows a stop (Klatt, 1975; Docherty, 1992; van Alphen \& Smits, 2004). By comparing the results, it can be seen that rate and context produce a very similar effect on VOT, and that the effect of phonetic context is also asymmetrical. Klatt (1975) reported that VOT (aspiration) in English voiceless stops was longer when it occurred before a sonorant consonant and shorter when it occurred before a vowel. VOT of voiceless unaspirated stops did not reveal this effect. Invoice languages a similar effect has been found on duration of prevoicing. For instance, in Dutch, van Alphen and Smits (2004) reported longer prevoicing in voiced stops in prevocalic position and shorter prevoicing in presonorant voiced stops. It was also demonstrated that VOT (prevoicing) increased in Russian voiced stops in prevocalic position, but VOT in voiceless stops did not change across phonetic contexts (Kulikov, 2012).

A relatively small number of studies have investigated temporal cues to voicing in word-medial stops. Lisker and Abramson (1967) claimed that glottal pulsing during stop closure was a major cue to the voicing category in wordmedial stops, similar to VOT in word-initial stops. However, the weight and implementation of closure voicingin languages may be different. Voicing in intervocalic stops in aspirating languages (e.g. English or German) is believed to be passive and variable, i.e. it occurs only because the voiced environment can induce excitation of the vocal folds (Westbury, 1983). As a result, voiced intervocalic stops in aspirating languages are often produced with incomplete voicing during closure (see Beckman, Jessen \& Ringen, 2013;Jessen \& Ringen, 2002, for German; Docherty, 1992, for British English; Lisker, 1986, for American English).

On the contrary, in true voice languages voicing is believed to be active (Beckman et al., 2011, Jessen \& Ringen, 2002), i.e. speakers may actively aim to produce a voicing gesture in phonologically voiced stops in all positions.

\footnotetext{
${ }^{1}$ Voice languages (e.g. Dutch, French, or Russian) have a contrast between prevoiced stops and voiceless unaspirated stops and may have a contrastive feature [voice] in phonology (Lombardi, 1995).Aspirating languages (e.g. English or German) have a contrast between voiceless aspirated stops voiceless unaspirated stops and may have a contrastive feature [spread glottis] in phonology (Iverson \& Salmons, 1995). 
As a result, closure voicing in voiced stops is more robust (Barry, 1995; Ringen \& Kulikov, 2012). For example, Ringen and Kulikov (2012) report that $97.5 \%$ of single intervocalic $b, d, g$ stops in Russian are produced with a fully voiced closure. In contrast to voiced stops, voicing in phonetically voiceless word-medial stops in both true voice and aspirating languages has a relatively short duration. It is typically realized as a short voice tail into an otherwise voiceless stop closure that continues from a preceding voiced segment.

The growing number of studies of voicing in word-medial obstruents in voice languages (e.g.Recasens \& Mira, 2012 for Polish;Strycharczuk,2015, for Catalan; Strycharczuk \& Simon, 2013, for West-Flemish) suggest that duration of closure voicing in these obstruents is also sensitive to phonetic context. More sonorant segments (vowels) provide an environment that facilitates voicing and allows for longer glottal pulsing in preceding stops. Glottal pulsing before less sonorous segments (sonorant consonants) is typically shorter across languages (Docherty, 1992; Kulikov, 2012; van Alphen \& Smits, 2004).

Duration of glottal pulsing in voiced word-medial stops in true voice languages also changes in response to speaking rate resulting in differences in duration of voicing between slow and fast rates. Kulikov (2012) reports that compared to the fast condition, duration of glottal pulsing in Russian intervocalic stops was longer by $27 \mathrm{msin}$ the list condition and by $20 \mathrm{~ms}$ in the slow condition. In voice languages, this increase in closure voicing is parallel to lengthening of VOT (prevoicing). In word-initial voiced stops, a phonologically motivated requirement to produce an active voicing gesture results in increase in duration of VOT (prevoicing) at slow rate. Likewise, lengthening of a word-medial obstruent in slower speech triggers lengthening of glottal pulses to ensure voicing during entire closure/frication.

It appears that contextual effects on duration of voicing in word-medial stops reveal marked similarities: they both cause lengthening of glottal pulsing in slower speech and in more sonorous environment. Notably, these effects are not limited to rate or sonority. Similar effects were found in stops in prominent prosodic positions, e.g. stressed syllables (Bradlow \& Smiljanić, 2009) or in clear speech (Smiljanić \& Bradlow,2008). Acoustical studies have revealed that higher sonority and slow speaking rate might provide configuration of the vocal tract that is conducive to vibration of the vocal folds(see Westbury \& Keating, 1986, for more detail). Thus, high sonority is a result of wider aperture of the vocal tract, which allows for greater volume of the oral cavity behind the main constriction. This, in turn, decreases supraglottal pressure, which ensures a longer time for glottal pulsing. The size of aperture of the vocal tract also changes at different speaking rates. Aperture is reduced in fast speech, at least in a non-high vowel environment, but it is typically wider in slow speech (Lindblom, 1983). The latter configuration may account forlonger glottal pulsing in voiced obstruents at slow rate.

Besides, previous studies have reported that the effect of speaking rate on duration of glottal pulsing is manifested not only as lengthening of voicing in slow speech (or shortening in fast speech) but also as variation in precision of articulatory gestures in fast speech. It has been shown that the ability of speakers to control accuracy decreases in faster, connected speech (Labov, 1972;Levelt, 1989), and that speakers tend to produce more speech errors in fast speech (Goldrick \& Blumstein, 2006). Interestingly, most of the speech errors in Goldrick and Blumstein's (2006) study were caused by misalignment between glottal pulsing and closure onset or offset. In line with these findings, Beckman et al. (2011) reported that each factor - syllable duration and speaking rate - had a separate significant effect on VOT duration in Swedish initial stops in response to rate manipulation, suggesting that the articulation of the speakers might be different in the two rate conditions. Together, these studies outline that additional variation in duration of glottal pulses in fast speech may also be caused by reduced motor control over timing of articulatory gestures.

\section{Voicing in Russian}

Russian is a convenient language to investigate variation in obstruent voicing. Russian is believed to have a [voice] contrast in obstruents between voiced and voiceless obstruents (Ringen \& Kulikov, 2012).Phonologically, the two voicing categories in Russian obstruents are believed to be discrete. Voiced stops are prevoiced, and voiceless stops are unaspirated, with short-lag VOT (Ringen \& Kulikov, 2012). Voicing in Russian largely depends on phonological context. The contrast in initial obstruents is preserved in both prevocalic and presonorant positions (Avanesov, 1968; Kn'azev, 2006), as shown in (1).
1) a. palka [p] 'stick'
b. srok [s] 'term'
balka [b] 'beam'
zloi [z] 'angry'

The contrast is also preserved in prevocalic/presonorant position word-internally, as shown in (2).
(2).a.
zapil [p] 'washed down' masc.
zabil [b] 'scored' masc.
b. vopros [p] 'question'
oblako [b] 'cloud' 
Word-internal morpheme and clitic boundaries are usually invisible for voicing processes (3). Final obstruents in prepositions preserve underlying voicing when occurring in a prevocalic/presonorant position

(3).a. nad \# oknom [d] 'over a window'

b. $\quad \mathrm{i} z$ \# lampy [zl] 'from the lamp

c. ot \# mgly [tmg] 'from haze'

The underlying contrast is neutralized in obstruent clusters. For example, if the underlying obstruent is voiceless but the following obstruent is voiced, voice assimilation occurs, and the segment is produced as voiced. The assimilatory change in obstruent-obstruent clusters is argued to be categorical, and phonological assimilation functions as a discrete rule (Cho, 1990).
(4) a. sadka [tk] 'cage' Gen.sg.
cf. sadok [d] 'cage' Nom.sg
b. ot\# goroda [dg] 'from the city' ot\# ugla [t] 'from the corner'

Phonetic implementation of voicing in obstruents, nevertheless, allows for some gradience. Although the duration of voicing in Russian stops averages 98\% of the closure (Ringen \& Kulikov, 2012), some intervocalic stops in Russian can be incompletely voiced (Barry, 1995) such that voicing occurs in a range between $55 \%$ and $100 \%$ of closure (Ringen \& Kulikov, 2012). Variation in closure voicing is greater in obstruents occurring in longer, obstruent-sonorantobstruent clusters (3c) than in regular presonorant stops (Kulikov, 2014). Gradience is also a natural outcome in assimilating obstruent clusters. Phonological voice assimilation is often incomplete in phonetics. Talkers can produce assimilated voiced obstruents with glottal pulsing for $60-90 \%$ of closure. Variation in closure voicing is also found in voiceless stops that can be voiced for more than $50 \%$ of their closure(Burton \& Robblee, 1997).

\section{Summary and Logic}

The goal of this paper is to evaluate magnitude of changes in duration of voicing (glottal pulses) in underlyingly voiced and voiceless Russian obstruents in response to (1) phonetic environments with different sonority and (2) speaking rate manipulation. It is hypothesized that duration of voicing in obstruents will gradually increase (i) in positions before a segment with higher sonority and (ii) in slower speaking rate.

It is expected that the greatest contrast (i.e. the difference between voicing duration in voiced and voiceless obstruents) will be found in position before vowels. The contrastive difference will decrease before segments with lower sonority (sonorant consonants). The underlying contrast will be largely neutralized before segments with the lowest sonority (obstruents), with minimal differences between underlying voiced and voiceless obstruents.

Speaking rate will affect voicing duration with the greatest contrast in the slow rate condition. The contrast could be partially neutralized in fast connected speech due to decrease in duration of glottal pulsing in underlying voiced obstruents. The changes in duration of glottal pulsing are expected to be asymmetrical: the effects of rate and phonetic context may be greater in underlyingly voiced obstruents. Changes in duration of voicing in underlyingly voiceless obstruents might be minimal.

Finally, it is hypothesized that speaking rate and sonority might interact, feeding each other to multiply their effect on duration of voicing. As a result, the longest duration of glottal pulsing is expected in most sonorous environment in slow speech.

Although the experimental design of this study aims to tackle the problems of gradience and variation in voicing categories, no single study can fully account for the entire range of these issues. This study is meant as a case study of the effects of context on the voicing contrast in a typical voice language.

\section{Method}

\section{Participants}

Fourteen monolingual native speakers of Russian, seven males and seven females, participated in the study. Their mean age was 19.0 years ( $S D=1.9$; range: 18-25 years). They had grown up and resided in Russia and spoke educated Standard Russian. The participants were naive as to the purpose of the experiment and had no history of speech or hearing disorders. They were paid a standard hourly rate for their participation in the study.

\footnotetext{
${ }^{2}$ Despite the claim that obstruents assimilate in voice through sonorants in these clusters (Jakobson, 1978), results of acoustic analyses (Kulikov, 2014; Robblee \& Burton, 1997) strongly support the variation hypothesis. 


\section{Items}

Test phrases $(n=78)$ included words with obstruents - stops $(n=36)$ and fricatives $(n=42)$ - in position before a vowel, sonorant, and obstruent within a word. Heterorganic stop clusters were used to reduce the number of unreleased stops. The examples of both types are shown in (5), and the full list of target phrasesis given in the Appendix.

$$
\begin{aligned}
& \text { nabor 'collection' } \\
& \text { posol'ambassador' } \\
& \text { kadra'frame' Gen.sg. } \\
& \text { kosmy 'matted hair' } \\
& \text { sadka 'cage' Gen.sg. } \\
& \text { kos'ba'mowing' }
\end{aligned}
$$

otmamy'from Mom'

nadramoj'over the frame'

otrtuti'from mercury'

nadmgloj'over haze'

sbakom'withacan'

izkarty'from the map'

In addition to single prevoicalic obstruents, three types of clusters appeared in the test phrases. This yielded to four types of phonetic environment: 1) the Vowel environment (e.g. /ba/, /pa/), 2) the Sonorant environment (e.g. /tra/, $/ \mathrm{tma} /, / \mathrm{dra} /, / \mathrm{dma} /), 3$ ) the Sonorant+Obstruent environment (e.g. /trd/, /drt/), and 4) the Obstruent environment (e.g. /tb/, /zk/). Both voiced and voiceless rightmost obstruents occurred in environments 3 and 4 to ensure a balanced result in voice assimilation, and both underlying voiced and voiceless target obstruents were produced before each voicing category of $\mathrm{C} 2 \mathrm{~s}$ (e.g. /tb/, /tp/, /zg/, /zk/). The environments were ranked according to sonority of the segment that immediately followed the target obstruent. The highest rank 4 was assigned to the position before a vowel; the lowest rank 1 was assigned to the position before an obstruent.

$\begin{array}{lccll}\text { (6) } & \text { Obstruent } & \text { Sonorant+Obstruent } & \text { Sonorant } & \text { Vowel } \\ \text { Rank: } & 1 & 2 & 3 & 4\end{array}$

\section{Procedure and Measurement}

The speakers were digitally recorded in a quiet environment using a one-point condenser SHURE WH30XLR placed approximately $20 \mathrm{~mm}$ away from the right corner of the mouth. The participants were asked to read the target phrases within a carrier phrase Skaži... ěšceraz 'Say ... again' in two speaking rate conditions: at a slow, comfortable tempo (hence, the slow condition); and at a fast tempo (hence, the fast condition). In the fast condition, the participants were instructed to speak as fast as they could but not at the expense of comprehensibility. The participants read the target phrases in each condition two times.

The segment boundaries were set manually in Praat (Boersma \& Weenink, 2011)using the waveform and the spectrogram, as shown in Figures1 and 2. The onset of the stop closure was marked at the end of the second formant structure, which typically coincides with a significant drop in amplitude of vocal fold vibration. The end of the closure was marked at the beginning of the release burst. Fricative duration was measured as the distance between the onset of frication noise and its offset. The onset of frication noise was determined by a change to a large amount of energy at high frequencies. The offset of frication was determined either by a decrease in high frequency energy before stop consonants or by the emergence of vocalic formant structure before a vowel. Duration of glottal pulses (or voicing duration) was measured as presence of the periodic portion of the obstruents on the waveform and the voicing bar on the spectrogram.

The total number of recorded target tokens was 4368 (78 target phrases x 14 talkers $\times 2$ speech conditions $\mathrm{x} 2$ readings). 104 tokens were later discarded due to mispronunciation, deletion, absence of audible and visible (on a spectrogram) release, metathesis, and nasalization. Measurements of the two repetitions of each token were averaged. A total of 2165 items were prepared for statistical analysis.

\section{Results}

The sections below present the results of statistical analyses. First, phrase duration was investigated to determine whether the speaking rate manipulation had the intended effect. Next, the effects of speaking rate and phonetic environment were examined using generalized mixed effects models and hierarchical regression analyses by looking at the duration of voicing in target obstruents. The results of statistical analyses are presented below. Only relevant effects and significant interactions are discussed.

\section{Phrase Duration and Rate}

The first set of analyses looked into the effect of the speech tempo on production of target phrases. The entire phrase length was used as a proxy for speaking rate and shorter phrase duration was expected with faster reading. A repeated measures ANOVA was used to evaluate (within-subjects) effects of speaking rate conditions (slow, fast), and underlying voicing type (voiceless, voiced) on phrase duration. 
A highly significant main effect of speaking rate was found $(F(1,13)=173.1, p<.0001)$. Speakers pronounced phrases in the fast condition at an average of $438 \mathrm{~ms}(S D=101)$, while in the slow condition they pronounced them over $100 \mathrm{~ms}$ slower, with average duration of $609 \mathrm{~ms}(S D=122)$. A significant main effect of voicing type was also found $(F(1,13)=$ $136.1, p<.001)$, and this effect did not interact with speaking rate $(F<1)$.Phrases with voiced target stops had on average longer duration $(M=590 \mathrm{~ms}, S D=160)$ than words with voiceless stops $(M=567 \mathrm{~ms}, S D=150)$. This difference might merely reflect the fact that prepositions with a voiced obstruent (e.g. nad 'over', iz 'out of') were longer than their counterparts with a voiceless obstruent (e.g. ot 'from', $s$ 'off').

\section{Effects of Context on Duration of Glottal Pulses}

The first set of analyses addressed the question on effects of the following segment and speaking rate on duration of voicing in obstruents. Box plots of distributions of voicing durations collapsed across (a) all rates and (b) all environments are shown in Figure 3.

The analysis was performed using a generalized linear mixed-effects modelin the IBM SPSS Statistics package, ver. 24.0. A mixed-effects model correctly accounts for variation in talkers and in tokens at the same time and can be used with missing and unbalanced data (Seltman, 2016), which often occurs in quasi-experimental designs.

Duration of voicing was the dependent variable in the model, and the effects of talker and item were treated as random. The model achieved the best fit with the fixed factors of underlying voicing (voiced, voiceless), environment (Vowel, Sonorant, Sonorant+Obstruent, Obstruent), speaking rate (slow, fast), and manner of articulation (stop, fricative).

When the model was fitted to the whole data set, all fixed effects reached high significance level $(p<.0001)$. However, due to interactions between underlying voicing, rate, and environment $(p<.001)$, these effects were analyzed separately in voiced and voiceless obstruents. In addition, a significant effect of manner reflected that duration of voicing in fricatives was $16 \mathrm{~ms}$ longer than in stops $(F(1,62.02)=5.02 ; p<.05)$, but manner of articulation did not interact with other factors, suggesting that stops and fricatives responded to differences in the environment and speaking rate in a similar fashion. Thus, the findings and tendencies in the following sections will be discussed in relation to all obstruents.

\section{Voiced Obstruents}

The analysis showed that voicing duration in underlying voiced $\mathrm{C} 1$ obstruents changed significantly as a function of phonetic environment $(F(3,1194.1)=153.0, p<.0001)$ and speaking rate $(F(1,1194.1)=153.0, p<.0001)$. The results are summarizedin Table 1.

The results demonstrate that voicing duration changed as a function of sonority of the following segment. In the slow rate, duration was the longest $(90 \mathrm{~ms})$ before a vowel, a segment with the highest sonority rank. Duration gradually decreased before segments with lower sonority rank, all positions being significantly different from the prevocalic position $(p<.0001)$. The difference between the two presonorant positions (Sonorant and Sonorant-Obstruent) was not significant $(p=.121)$. The shortest voicing duration was in obstruent-obstruent clusters, the phonetic environment with the lowest sonority $(\beta=-58, S E=3.7, t=-15.7, p<.001)$.

\section{Voiceless Obstruents}

The results of the analysis for duration of glottal pulses in underlying voiceless C1 obstruents are summarized in Table 2. The analysis showed that duration of glottal pulses in underlying voiceless $\mathrm{C} 1$ obstruents changed as a function of phonetic environment $(F(3,26.0)=3.9, p<.05)$, but a series of post-hoc tests revealed that duration of glottal pulses significantly increased only in obstruent-obstruent clusters. It was $17 \mathrm{~ms}$ longer than in prevocalic and presonorant obstruents $(S E=3.0, t=5.8, p<.0001)$. Duration of voicing in both presonorant positions averaged $13 \mathrm{~ms}$ and was not significantly different from voicing in prevocalic position $(t<1)$.

No effect of rate was obtained $(t<1)$, but the interaction between speaking rate and environment revealed that duration of the glottal pulses increased in faster speech in obstruent-sonorant-obstruent clusters $(\beta=10.4, S E=3.8, t=2.7$, $p<.01)$. It is of note that this change occurred in the opposite direction than in voiced obstruents, where duration of voicing typically decreased in faster speech. Therefore, this change may be caused by factors other than sonority or speaking rate.

\section{Comparing Variation in Glottal Pulsing Duration}

The last set of analyses examined relative weight of effects of sonority and speaking rate in the two categories of obstruents. This was done using a hierarchical regression model, in which a single variable enters a model in a step-by step fashion. Unlike ANOVAs, regression models can provide proportions of explained variance, allowing for direct comparison of effects of each independent variable in the two sets of items. At each step, the $R^{2}$ statistic was calculated as a measurement of variation explained by a predictor variable. 
In this analysis, speaking rate is treated as a continuous variable, using duration of a phrase as a proxi. Recall that talkers pronounced significantly longer phrases in slower speech. A similar trend was observed for duration of glottal pulses. Therefore, a strong linear relation between duration of glottal pulsing and phrase duration is expected in cases when the effect of speaking rate is significant. The data were slightly modified for this analysis. Measurements were collapsed across phrases to reduce the number of items. Hence, a total of 448 items were prepared for analysis.

Underlyingly voiced and voiceless obstruents were analyzed separately with the same linear regression model. The model tested duration of glottal pulsing (the dependent variable) against five independent (predictor) variables: talker, phrase duration, speaking rate, manner of articulation, and phonetic environment. In addition, interactions between environment and phrase duration and between environment and rate were added to the model. The summary of $R^{2}$ change statistics is presented in Table 3 .

First, the model was applied to the set of underlyingly voiceless obstruents. Overall, it explained $70 \%$ of variance in duration of glottal pulsing $(F(25,198)=18.3, p<.0001)$. In the first step, 13 dummy codes for talkers were added to the model to account for speaker variance, which explained $10 \%$ of variation in duration of glottal pulsing $\left(F_{\text {change }}(13,210)=1.79, p<.05\right)$. In the second step, manner of articulation accounted for additional $2 \%$ of variance $\left(F_{\text {change }}(1,209)=4.92, p<.05\right)$, confirming the fact that duration of voicing in fricatives was $3.5 \mathrm{~ms}$ longer than in stops. Next, phrase duration accounted for $0.6 \%$ of variance, which was not significant $\left(F_{\text {change }}(1,208)=1.37\right.$, $p=.243)$. Then, rate itself accounted for $12 \%$ of variance $\left(F_{\text {change }}(1,207)=32.1, p<.0001\right)$. The difference between the two conditions was $16 \mathrm{~ms}$. Phonetic environment explained $39.5 \%$ of variance $\left(F_{\text {change }}(3,204)=74.4, p<.0001\right)$. Duration of voicing tail in the obstruent condition was $18 \mathrm{~ms}$ longer $(p<.0001)$ than in prevocalic/presonorant conditions. Finally, the interactions between environment and phrase duration accounted for additional $6 \%$ of variance $(p<.0001)$, revealing that these changes were implemented differently in some environments.

Then, the same model was applied to the set of underlyingly voiced obstruents. Overall, it explained $86 \%$ of variance in duration of glottal pulsing $(F(25,198)=47.8, p<.0001)$. In the first step, dummy codes for talkers accounted for $6.9 \%$ of variation in duration of glottal pulsing, a non-significant result $\left(F_{\text {change }}(13,210)=1.2, p=.281\right)$. In the second step, manner of articulation explained additional $13.6 \%$ of variance $\left(F_{\text {change }}(1,209)=35.7, p<.0001\right)$, confirming the fact that duration of voicing in fricatives was $14 \mathrm{~ms}$ longer than in stops. Next, phrase duration explained $4.4 \%$ of variance $\left(F_{\text {change }}(1,208)=12.3, p<.001\right)$. Glottal pulsing increased $.04 \mathrm{~ms}$ for every ms of phrase duration. Then, rate itself accounted for $19.4 \%$ of variance $\left(F_{\text {change }}(1,207)=72.3, p<.0001\right)$. The difference between the two conditions was $19 \mathrm{~ms}$. Phonetic environment explained $39.5 \%$ of variance $\left(F_{\text {change }}(3,204)=137.9, p<.0001\right)$. Slopes in the two presonorant conditions and in the obstruent condition were significantly smaller (Sonorant: $\beta=-15 \mathrm{~ms}, t=-7.06, p<$ .0001 ; Sonorant+Obstruent: $\beta=-19 \mathrm{~ms}, t=-5.26, p<.0001$; Obstruent: $\beta=-41 \mathrm{~ms}, t=-17.4, p<.0001$ ) than in the prevocalic condition. These differences were confirmed by significant interaction between environment and phrase duration, which accounted for additional $4 \%$ variance $\left(F_{\text {change }}(3,201)=16.5, p<.0001\right)$.

\section{Interim Summary}

The results confirmed the predictions that duration of glottal pulses responds to changes in phonetic environment and in speaking rate. In addition, the analysis revealed another important trend, as illustrated in Figure 7. The changes induration of glottal pulsing are manifested differently in underlyingly voiced and voiceless obstruents. In voiced obstruents (Fig.7b), duration of glottal pulses changed as a function of sonority of the following segment and as a function of speaking rate increasing along both dimensions. Talkers produced longer glottal pulsing in voiced obstruents before more sonorous segments (vowels and sonorants). The shortest mean duration of voicing was found in obstruent-obstruent clusters, which have the lowest sonority rank. Duration of voicing also increased in slower speech. In fast speech, duration of voicing was shorter in all phonetic environments.

The pattern observed in underlyingly voiceless obstruents (Fig.7a) was different. The analysis did not find significant effects of speaking rate on voicing in underlyingly voiceless obstruents. Voicing duration changed in response to rate only in the Sonorant-Obstruent condition, but intriguingly, duration of glottal pulses in these obstruents was longer in the fast speech. In addition, significant variation among speakers was found in production of glottal pulses in voiceless obstruents.

It is of note, that the effect of rate does not include only lengthening or shortening of glottal pulsing as speech becomes slower or faster. This trend was found only in underlyingly voiced obstruents (section 6.3), suggesting the changes are phonologically motivated.

The results show that sonority and speaking rate interact, as the magnitude of changes in response to sonority is smaller in faster speech. The nature and direction of the interaction is described in the next section. 


\section{Interaction between Phonetic Environment and Speaking Rate}

Recall that talkers produced longer glottal pulsing in slower speech and in more sonorous phonetic environments and shorter glottal pulsing in faster speech and in less sonorous phonetic environments. To investigate possible mutual influence of the factors, the estimates of significant slope coefficients for each rate and environment condition from the previous analysis were compared. The differences between conditions were put on a two-dimensional matrix, as shown in Table 4.

The rows represent parameter estimates in the three phonetic environments with sonority increasing from top to bottom. As duration of glottal pulsing was the shortest in the Obstruent environment in fast speech, this condition is used as an intercept that is set as azero point in the matrix. The bold numbers in white cells present the differences in glottal pulsing between the zero point and each condition. For example, duration of glottal pulsing in the Obstruent environment in slow speech was on average $7 \mathrm{~ms}$ longer than in fast speech. Similarly, duration of glottal pulsing in the Sonorant environment was $20 \mathrm{~ms}$ longer than in the Obstruent environment in fast speech, but the difference between the Sonorant environment in slow speech and the zero was $35 \mathrm{~ms}$. The maximum difference from zero (57 ms) occurred when obstruents were produced before a vowel in slow speech. The numbers in italics in blue shaded cells are increments of differences between two adjacent positions.

Although duration of glottal pulsing increased along both dimensions, i.e. as a function of sonority of the following segment and speaking rate, the increments were not monotonic. The increment was the greatest between the assimilating (Obstruent) and contrastive (Sonorant) conditions at each rate (Fast: $20 \mathrm{~ms}$; Slow: $28 \mathrm{~ms}$ ). The increments between the Sonorant and Vowel environments, in which phonological transformations of segments do not occur, were smaller (Fast: $13 \mathrm{~ms}$; Slow: $22 \mathrm{~ms}$ ).

Comparison between the two rate conditions in each environment suggests that the effect of speaking rate enhances the phonological contrast, as the increments between the two phonological conditions are greater in slow speech. The same can be said about the role of phonetic environment: low sonority of the following segment in the Obstruent condition suppresses and eventually neutralizes the underlying contrast, whereas higher sonority of the following segment in the Sonorant and Vowel conditions enhances the contrast.

In addition, the pattern reveals that sonority enhances the effect of rate. In the Obstruent condition, where the sonority is the lowest, the difference between the two rates was the smallest $(7 \mathrm{~ms})$. In phonetic environments with higher sonority, the differences between the fast and slow rates were significantly higher (15 and $24 \mathrm{~ms}$ ).

Finally, the increase in duration of glottal pulsing between fast and slow rates is comparable to the increase in duration of glottal pulsing between the Sonorant and Vowel conditions. Switching the rate from the Sonorant-Fast to SonorantSlow condition increased duration of glottal pulsing by the 15 msincrement; switching to a higher sonority rank from the Sonorant-Fast to Vowel-Fast condition increased it by $13 \mathrm{~ms}$. Likewise, the $24 \mathrm{~ms}$ increment between the VowelFast and Vowel-Slow conditions is very similar to the 22 msincrement between the Sonorant-Slow and Vowel-Slow conditions. The striking similarity suggests that changes in duration of glottal pulsing in obstruents as a function of speaking rate and sonority may be regulated by the same or similar articulatory principles.

\section{Discussion}

The goal of this paper was to investigate contextual effects of speaking rate and sonority of phonetic environment on duration of voicing in Russian word-medial obstruents. The results indicate that both speaking rate and sonority of the following segment affect duration of glottal pulses in obstruents. In addition, the current study reveals a complex pattern of changes in duration of glottal pulsing due to the underlying voicing category of an obstruent. The main effects of speaking rate and phonetic environment were found only in underlyingly voiced obstruents; glottal pulsing in underlyingly voiceless obstruents was largely unaffected by these factors.

Previous studies of VOT in stops (Beckman et al., 2011; Kessinger \& Blumstein, 1997; Magloire \& Green, 1999, among others) suggest that the asymmetrical rate effects can be accounted for by phonological patterns in languages. Rate effects on VOT were observed in stops specified with phonological features [spread glottis] (Iverson \& Salmons,1995) and [voice](Lombardi, 1995). Voiceless unaspirated stops across languages are believed not to be specified in phonology (Iverson \& Salmons, 1995), which is why short-lag VOT in voiceless unaspirated stops may show no effect of rate. The findings of the current study provide additional evidence for this claim and extend generalizations about VOT to another cue, i.e. closure/frication voicing. The results suggest that the effect of speaking rate manipulation on duration of glottal pulses in word-medial obstruents is similar to the effect of speaking rate on prevoicing (VOT) in word-initial stops. Duration of glottal pulsing increased in underlyingly voiced stops as speech slowed. But duration of voicing in phonologically unspecified voiceless obstruents in Russian was not affected by changes in the speaking rate. The results of the current study are consistent with the claim in Beckman et al. (2011). 
Since underlyingly voiced stops in Russian are assumed to be specified with privative [voice] (Lombardi, 1995), the increase in durationshould be found in the temporal cue linked to this phonological feature.

Therefore, longer glottal pulsing during closure in medial obstruents is a predicted result in a voice language. The increase in duration of glottal pulses in voiced word-medial obstruents found in the current study might be driven by the same requirement to use active voicing gesture(s) in order to enhance a phonological contrast (Stevens\& Keyser, 1989).

Another important finding of the current study is that changes in duration of glottal pulses in response to rate manipulation are likely to be an aftermath of two different processes. The results suggest that the mechanisms of controlling speaking rate may include changes other than lengthening or shortening glottal pulsing in slow or fast speech. In addition to changes in duration, the two rates may be different in efforts of the talker to control coordination and timing of articulatory gestures (Labov, 1972). Under this assumption, greater effect of speaking rate in underlyingly voiced obstruents is an aftermath of the closer attention of the talkers to the voicing gesture.

The asymmetrical pattern of changes in duration of glottal pulses was also observed in response to sonority of phonetic environment. Duration of glottal pulsing increased significantly before segments with high sonority rank only in underlyingly voiced obstruents. In underlyingly voiceless obstruents, duration of glottal pulses did not change in prevocalic/presonorant positions. The results of the current study are also consistent with other studies that investigated duration of voicing in presonorant obstruents in other [voice] languages, e.g. Polish (Recasens \& Mira, 2012), WestFlemish (Strycharczuk \& Simon, 2013), or Catalan (Strycharczuk, 2015).

The results are consistent with phonological theories that argue for parallel processes in the phonological and phonetic components of grammar (e.g. Flemming, 2001). The findings of the current study support the argument that phonological voice assimilation in a language may emerge from gradient neutralizing phonetic effects of low sonority on voicing in obstruent clusters. The observed pattern of voicing suggests that this effect is encoded in Russian phonology. At the extremes of the sonority scale the results are discrete and categorical: the underlying laryngeal contrast is maintained before segments with high sonority (vowels and sonorants), whereas voice assimilation transforms the underlying category of the obstruent before segments with low sonority (obstruents). In the presonorant (contrastive) positions phonetic gradience is used to enhance the phonological contrast rather than to neutralize it.

The data support a long-standing view that obstruents in Russian retain underlying voicing category in prevocalic/presonorant position, but they typically assimilate in voicing to the obstruent that immediately follows (Avanesov, 1968; Kn'azev, 2006). All presonorant positions, including obstruent-sonorant-obstruent clusters, revealed a robust difference in duration of voicing between underlyingly voiced and voiceless obstruents. The results do not provide empirical support for claims in Jakobson (1978) about "sonorant transparency" to voice assimilation in Russian. Rather, the findings suggest that "sonorant transparency" might be a phonetic artefact emerging from two independent factors: (1) greater variability in duration of voicing found in Kulikov (2014) and (2) increase in duration of voicing in voiceless obstruents in longer clusters in faster speech (this study). Although the two processes may be driven by different articulatory mechanisms, they have the same effect of partially neutralizing the underlying contrast in phonetics.

Finally, the findings indicate that both contextual factors, speaking rate and sonority of a following segment, may provide a cumulative effect on voicing in obstruents. Glottal pulsing is the longest when an obstruent is produced before a vowel in slow speech. It seems plausible to assume that the two effects were added because they are likely to be governed by the same acoustical properties. Slower and clearer speech is conducive to enhancement of a phonological contrast not only in a temporal dimension (i.e. producing longer glottal pulsing). It facilitates voicing because it also provides configuration of the vocal tract that facilitates vibration of the vocal folds. Aperture of the vocal tract is wider in slower speech. This, in turn, decreases supraglottal pressure allowing for longer period of glottal pulsing (Westbury \& Keating, 1986). The size of aperture is a physical property that is also linked to sonority. More sonorous segments are characterized by wider opening of the vocal tract. Therefore, lengthening duration of glottal pulses before more sonorous segments might be an efficient strategy in order to enhance the [voice] contrast. The results are consistent with the "licensing by cue" hypothesis (Steriade, 1997), but they depart from it in that they demonstrate enhancement of a laryngeal phonological contrast in cues other than stop release.

\section{Conclusions}

This study aimed to advance the understanding of contextual effects of speaking rate and phonetic environment on closure/frication voicing in obstruents in a voice language. Overall, the results presented empirical support for the hypothesis that voicing in word-medial obstruents is affected by context. 
The effects of speaking rate and phonetic environment on glottal pulsing during closure/frication were shown to be similar to the effects of rate and phonetic context on VOT in initial stops. The findings also demonstrate that changes in obstruent voicing in response to rate and sonority of the following segment may be governed by phonological requirements. Talkers produced longer prevoicing and longer closure voicing in stops specified with [voice] in Russian. The results should be of interest to phoneticians and phonologists because they provide insights into how phonological patterns may emerge from phonetic variation. Specifically, phonological voice assimilation may start from a neutralizing effect of phonetic context on duration of voicing in obstruent clusters. A natural progression of this work is to analyze some controversial claims about Russian phonology, e.g. a "schizophrenic" nature of the Russian fricative $[\mathrm{v}]$ in processes of voice assimilation. Further research in this area may lead to understanding the effects of context on voicing in clusters with [v], which has properties of both an obstruent and a sonorant in Russian.

\section{References}

Allen, J. S., \& Miller, J. L. (1999). Effects of syllable-initial voicing and speaking rate on the temporal characteristics of monosyllabic words. Journal of the Acoustical Society of America, 106, 2031-2039.

Alphen, P. M.van, \& Smits, R. (2004). Acoustical and perceptual analysis of the voicing distinction in Dutch initial plosives: The role of prevoicing. Journal of Phonetics, 32(4), 455-491.

Avanesov, R. I. (1968). Russkoe Literaturnoe Proiznoshenie. Moscow: Prosveshchenie.

Barry, S. M. E. (1995). Variation in vocal fold vibration during voiced obstruents in Russian. European Journal of Disorders in Communication, 30, 124-131.

Beckman, J., Helgason, P., McMurray, B., \& Ringen, C. (2011). Rate effects on Swedish VOT: Evidence for phonological overspecification. Journal of Phonetics, 39, 39-49.

Beckman, J., Jessen, M., \& Ringen, C. (2013). Empirical evidence for laryngeal features: Aspirating vs. true voice languages. Journal of Linguistics, 49(2), 259-284.

Bradlow, A. R., \&Smiljanić, R. (2009).Speakingandhearingclearly:Talkerandlistener factors inspeakingstylechanges. Language and Linguistics Compass, 3, 236-264.

Boersma, P., \& Weenink, D. (2011). Praat: Doing phonetics by computer (Version 5.2.15). Retrieved from http://www.praat.org/

Burton, M. W., \& Robblee, K. E. (1997). A phonetic analysis of voicing assimilation in Russian. Journal of Phonetics, $25,97-114$.

Cho, Y.-m. Y. (1990). A typology of voicing assimilation. In A. Halpern (Ed.), WCCFL 9: The Proceedings of the Ninth West Coast Conference on Formal Linguistics (pp. 141-155). Stanford University.

Chomsky, N., \& Halle, M. (1968). The Sound Pattern of English. New York: Harper \& Row.

Cole, J. S., Linebaugh, G., Munson, C., \& McMurray, B. (2010). Unmasking the acoustic effects of vowel-to-vowel coarticulation: A statistical modeling approach. Journal of Phonetics, 38(2), 167-184.

Docherty, G. J. (1992). The timing of voicing in British English obstruents. Berlin: Foris.

Flemming, E. (2001). Scalar and categorical phenomena in a unified model of phonetics and phonology. Phonology, $18,7-44$.

Goldrick, M., \& Blumstein, S. E. (2006). Cascading activation from phonological planning to articulatory processes: Evidence from tongue twisters. Language and Cognitive Processes, 21, 649-683.

Gow, D. W. (2001). Assimilation and Anticipation in continuous spoken word recognition. Journal of Memory and Language, 45, 133-139.

Gow, D. W., \& McMurray, B. (2007). Word recognition and phonology: The case of English coronal place assimilation. . In J. S. Cole \& J. Hualdo (Eds.), Papers in Laboratory Phonology 9 (pp. 173-200). New York, NY: Mouton de Gruyter.

Iverson, G. K., \& Salmons, J. C. (1995). Aspiration and laryngeal representation in Germanic. Phonology, 12, 369-396. Jakobson, R. (1978). Mutual assimilation of Russian voiced and voiceless consonants. Studia Linguistica, 32, $107-110$. Jessen, M., \& Ringen, C. (2002). Laryngeal features in German. Phonology, 19(2), 189-218.

Kessinger, R. H., \& Blumstein, S. E. (1997). Effects of speaking rate on voice-onset time in Thai, French, and English. Journal of Phonetics, 25(2), 143-168.

Klatt, D. H. (1975). Voice onset time, frication, and aspiration in word-initial consonant clusters. Journal of Speech and Hearing Research, 18, 686-706.

Kn'azev, S. V. (2006). Struktura fonetičeskogo slova v russkom jazyke: Sinxronija i diaxronija. Moscow: Izd-vo MaksPress.

Kulikov, V. (2012). Voicing and voice assimilation in Russian stops (Doctoral dissertation), University of Iowa. 
Kulikov, V. (2014). Voicing contrast in consonant clusters: Evidence against sonorant transparency to voice assimilation in Russian. Phonology, 30(3), 423-452.

Labov, W. (1972). Language in the Inner City: Studies in the Black English Vernacular. Philadelphia: University of Pennsylvania Press.

Levelt, W. J. M. (1989). Speaking: from intention to articulation. Cambridge, MA: The MIT Press.

Lindblom, B. (1983). Economy of speech gestures. In P. F. MacNeilage (Ed.), The production of speech (pp. 217-245). New York: Springer-Verlag.

Lisker, L. (1986). "Voicing" in English: A catalogue of acoustic features signaling /b/ versus /p/ in trochees. Language and Speech,19, 3-11.

Lisker, L., \& Abramson, A. S. (1964). A cross-language study of voicing in initial stops: acoustical measurements. Word, 20, 384-422.

Lisker, L., \& Abramson, A. S. (1967). Some effects of context on voice onset time in English stops. Language and Speech, 10, 1-28.

Lombardi, L. (1995). Laryngeal features and provativity. The Linguistic Review, 12, 35-59.

Magloire, J., \& Green, K. P. (1999). A cross-language comparison of speaking rate effects on thr production of voice onset time in English and Spanish. Phonetica, 56, 158-185.

Ohala, J. (1996). Speech perception is hearing sounds, not tongues. Journal of the Acoustical Society of America, 99(3), $1718-1725$.

Pierrehumbert, J. B. (2003). Phonetic diversity, statistical learning, and acquisition of phonology. Language and Speech, 46, 115-154.

Recasens, D., \& Mira, M. (2012). Voicing assimilation in Catalan two-consonant clusters. Journal of Phonetics, 40(5), 639-654.

Ringen, C., \& Kulikov, V. (2012). Voicing in Russian stops: Cross-linguistic implications. Journal of Slavic Linguistics, 20(2), 269-286.

Robblee, K. E., \& Burton, M. W. (1997). Sonorant voicing transparency in Russian Annual Workshop on Formal Approaches to Slavic Linguistics. The Cornell meeting 1995 (pp. 407-434).

Seltman, H. J. (2016). Experimental design and analysis.

[Online]Available:http://www.stat.cmu.edu/ hseltman/309/Book/(June 3, 2016)

Smiljanić, R.\& Bradlow, A. R.(2008). Stability of temporal contrasts across speaking styles in English and Croatian. Journal of Phonetics 36, 91-113.

Smolensky, P., Goldrick, M., \& Mathis, D. (2014). Optimization and quantization in gradient symbol systems: A framework for integrating the continuous and the discrete in cognition. Cognitive Science,38, 1102-1138.

Steriade, D. (1997). Phonetics in phonology: The case of laryngeal neutralization. Ms.

Stevens, K. N., \& Keyser, S. J. (1989). Primary features and their enhancement in consonants. Language, 65(1), 81106.

Strycharczuk, P. (2015). Manner asymmetries in Central Catalan pre-vocalic voicing. Language Sciences, 47, 84-106.

Strycharczuk, P., \& Simon, E. (2013). Obstruent voicing before sonorants: The case of West-Flemish. Natural Language \& Linguistic Theory, 31(2), 563-588.

Westbury, J. R. (1983). Enlargement of the supraglottal cavity and its relation to stop consonant voicing. Journal of the Acoustical Society of America, 73(4), 1322-1336.

Westbury, J. R., \& Keating, P. A. (1986). On the naturalness of stop consonant voicing. Journal of Linguistics, 22(1), $145-166$.

\section{Sponsorship:}

This work was supported in part by Qatar University under grant QUSG-CAS-DELL-14\15-23. Support for theRussian data collection was provided by the T. Anne Cleary International Dissertation Research Fellowship (2010) from the University of Iowa. 


\section{Appendix: List of items}

$\begin{array}{ll}\text { Vowel } & \\ \text { /p/ } & \text { napor 'pressure' } \\ \text { /b/ } & \text { nabor 'set' } \\ \text { /t/ } & \text { motor 'engine' } \\ \text { /d/ } & \text { zador 'ardor' } \\ \text { /g/ } & \text { bagor 'hook' } \\ \text { /k/ } & \text { zakon 'law' } \\ \text { /f/ } & \text { plafon 'lamp shade' } \\ \text { /v/ } & \text { ugovor 'bargain' } \\ \text { /s/ } & \text { posol 'ambassador' } \\ \text { /z/ } & \text { zazor 'clearance' }\end{array}$

\section{Sonorant}

/pr/ kopra 'copra'

/br/ kobra 'cobra'

/tr/ teatra 'theater' Gen.sg.

/dr/ kadra 'frame' Gen.sg.

/kr/ fiakra 'fiacre' Gen.sg.

/gr/ onagry 'onagers'

/fr/ cyfra 'digit'

/vr/ lavra 'laura'

/sm/ kosmy 'matted hair'

/zm/ spazmy 'spasms'

\section{Obstruent}

/tk/ katka 'skating rink'

/dk/ sadka 'cage'Gen.sg.

/db/ gorod'ba 'fence'

/tb/ molot'ba 'threshing'

/sk/ noska 'sock'Gen.sg.

/zk/ mazka 'stroke'Gen.sg.

/sb/ kos'ba 'mowing'

/zb/ rez'ba 'thread'
Clitics:

$/ \mathrm{t} / \quad$ ot 'from

/d/ nad 'over'

/s/ s 'from', 'with'

/z/ iz 'from'

/v/ v 'in'

These prepositions were used in combination with the following nouns:

\begin{tabular}{|c|c|}
\hline Sono & \\
\hline$/ \mathrm{m} /$ & $\begin{array}{l}\text { mama 'mom' } \\
\text { more 'sea' }\end{array}$ \\
\hline$/ \mathrm{r} /$ & $\begin{array}{l}\text { rama 'frame' } \\
\text { rol' 'role' }\end{array}$ \\
\hline /1/ & lampa 'lamp' \\
\hline Sono & $n t+O b s t r u e n t$ \\
\hline$/ \mathrm{mz} /$ & mzda 'bribe' \\
\hline$/ \mathrm{r} 3 /$ & Ržev 'Rzhev’ \\
\hline /ld/ & 1'dina 'ice floe' \\
\hline /lg/ & lgun’ja ‘liar’ fem. \\
\hline$/ \mathrm{mx} /$ & mxa/mxom 'moss' Gen./Instr. \\
\hline$/ \mathrm{mts} /$ & Mcensk 'Mtsensk' \\
\hline$/ \mathrm{rt} /$ & rtut' 'mercury' \\
\hline Obstr & \\
\hline /b/ & bak 'can' \\
\hline$/ d /$ & dom 'house' \\
\hline /g/ & $\begin{array}{l}\text { gaz 'gas' } \\
\text { gore 'distress' }\end{array}$ \\
\hline$/ \mathrm{p} /$ & par 'steam' \\
\hline & pole 'field' \\
\hline$/ \mathrm{k} /$ & karta 'map' \\
\hline & koma 'coma' \\
\hline
\end{tabular}

\section{Tables}

Table 1. Summary of the fixed part of the linear mixed-effects model predicting the duration of glottal pulses in voiced obstruents. The intercept represents duration of glottal pulsing before a vowelat slow rate.

\begin{tabular}{llrrrr}
\hline \hline Fixed factor $(d f)$ & Level & \multicolumn{1}{c}{$\beta$} & $S E$ & \multicolumn{1}{c}{$t$} & $p$ \\
\hline \hline Intercept & & 90.3 & 3.5 & 26.1 & .000 \\
Environment (3) & Sonorant & -28.5 & 3.8 & -7.5 & .000 \\
& Sonorant-Obstruent & -35.7 & 4.0 & -9.0 & .000 \\
& Obstruent & -58.0 & 3.7 & -15.7 & .000 \\
Rate (1) & Fast & -28.7 & 3.9 & -7.3 & .000 \\
Environment * Rate (3) & Fast: Sonorant & 12.8 & 4.6 & 2.8 & .005 \\
& Fast: Sonorant+Obstruent & 18.1 & 4.6 & 4.0 & .000 \\
& Fast: Obstruent & 24.5 & 4.4 & 5.6 & .000 \\
\hline \hline
\end{tabular}


Table 2. Summary of the fixed part of the linear mixed-effects model predicting the duration of glottal pulses in voiceless obstruents. The intercept represents duration of glottal pulsing before a vowel at slow rate.

\begin{tabular}{llrrrr}
\hline \hline Fixed factor $(d f)$ & Level & \multicolumn{1}{c}{$\beta$} & $S E$ & \multicolumn{1}{c}{$t$} & $p$ \\
\hline \hline Intercept & & 14.8 & 2.6 & 5.6 & .000 \\
Environment (3) & Sonorant & -1.0 & 3.1 & -0.3 & .753 \\
& Sonorant+Obstruent & -1.0 & 3.2 & -0.3 & .745 \\
& Obstruent & 17.1 & 3.0 & 5.8 & .000 \\
Rate (1) & Fast & -2.1 & 1.9 & -1.2 & .250 \\
Environment * Rate (3) & Fast: Sonorant & -4.1 & 3.6 & -1.1 & .251 \\
& Fast: Sonorant+Obstruent & 10.4 & 3.8 & 2.7 & .007 \\
& Fast: Obstruent & 1.8 & 3.7 & 0.5 & .636 \\
\hline \hline
\end{tabular}

Table 3. Summary of $R^{2}$ change statistics for independent variables in a linear hierarchical regression model predicting duration of glottal pulsing by phrase duration in underlyingly voiceless and voiced obstruents.

\begin{tabular}{lllll}
\hline \hline Predictor & Voiceless & \multicolumn{3}{c}{ Voiced } \\
\hline \hline Talker & $\mathbf{. 1 0 0}$ & $*$ & .069 & ${ }^{* * * * *}$ \\
Manner & $\mathbf{. 0 2 1}$ & & $\mathbf{. 1 3 6}$ & ${ }^{* * * *}$ \\
\hline \hline Phrase duration & .006 & & $\mathbf{0 4 4}$ & ${ }^{* * * *}$ \\
Rate & $\mathbf{. 1 1 7}$ & ${ }^{* * * *}$ & $\mathbf{. 1 9 4}$ & ${ }^{* * * * *}$ \\
Phonetic environment & $\mathbf{. 3 9 5}$ & $* * *$ & $\mathbf{. 3 7 3}$ & ${ }_{* * * * *}^{* * *}$ \\
Phonetic environmentx Phrase duration & $\mathbf{. 0 3 3}$ & & $\mathbf{. 0 3 6}$ & \\
\hline \hline
\end{tabular}

Note: significance codes: $* \mathrm{p}<.05, * * \mathrm{p}<.01, * * * \mathrm{p}<.001, * * * * \mathrm{p}<.0001$.

Table 4. The matrix of differences in duration of glottal pulsing (ms) between phonetic environments (with sonority ranks) and speaking rates. Significant parameter estimates $(\beta)$ are shown in bold in white cells. Numbers in italics in blue shaded cells represent differences (increments) between adjacent parameter estimates.

\section{Speaking rate}

\begin{tabular}{|c|c|c|c|}
\hline \multirow{3}{*}{1 Obstruent } & Fast & & low \\
\hline & 0 & 7 & 7 \\
\hline & 20 & & 28 \\
\hline \multirow[t]{2}{*}{3 Sonorant } & 20 & 15 & 35 \\
\hline & 13 & & 22 \\
\hline 4 Vowel & 33 & 24 & 57 \\
\hline
\end{tabular}



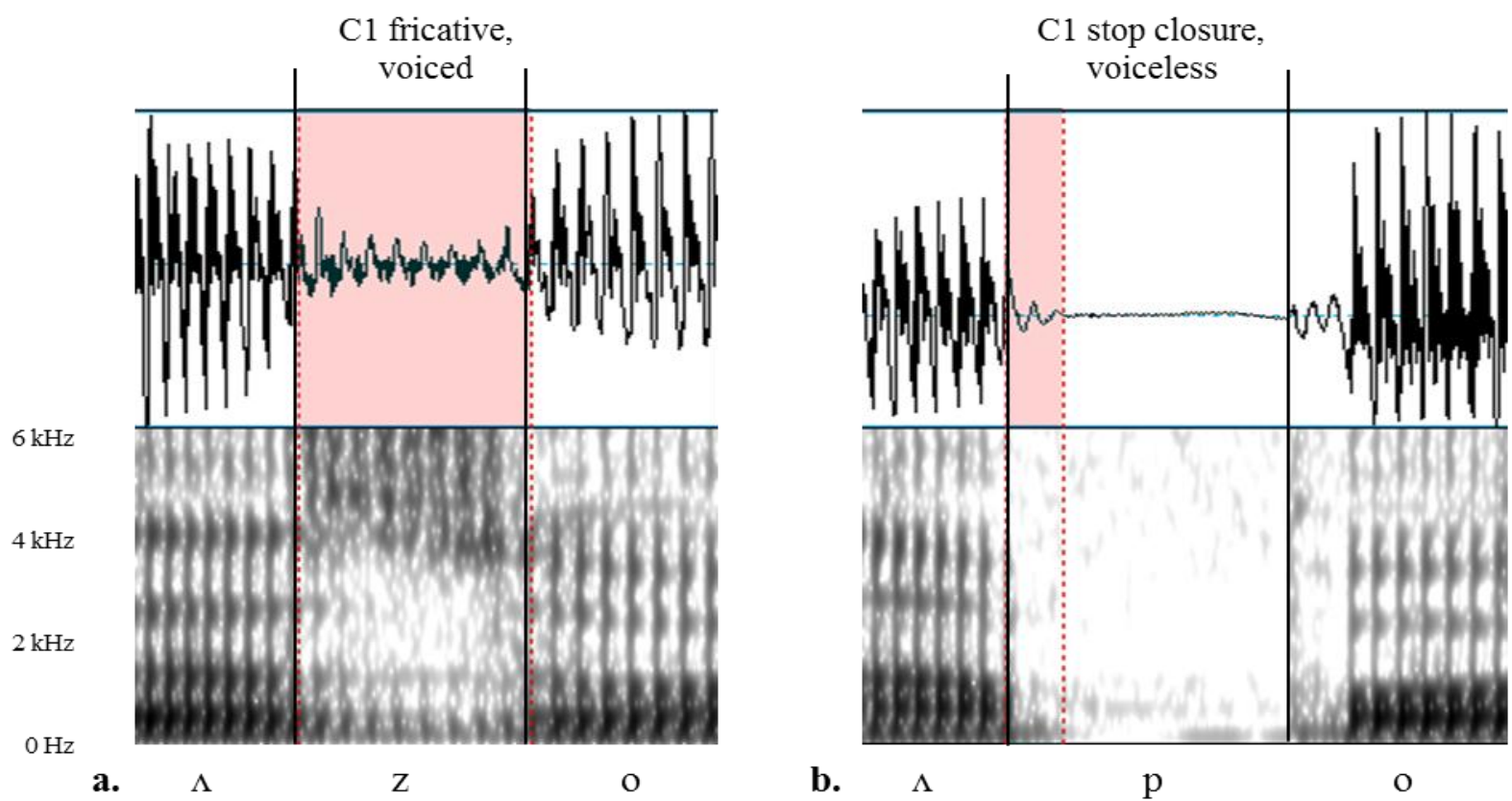

\section{Figures}

Figure 1. Examples of acoustic measurements insingle voiced and voiceless target prevocalic obstruents: (a)zazor[z]
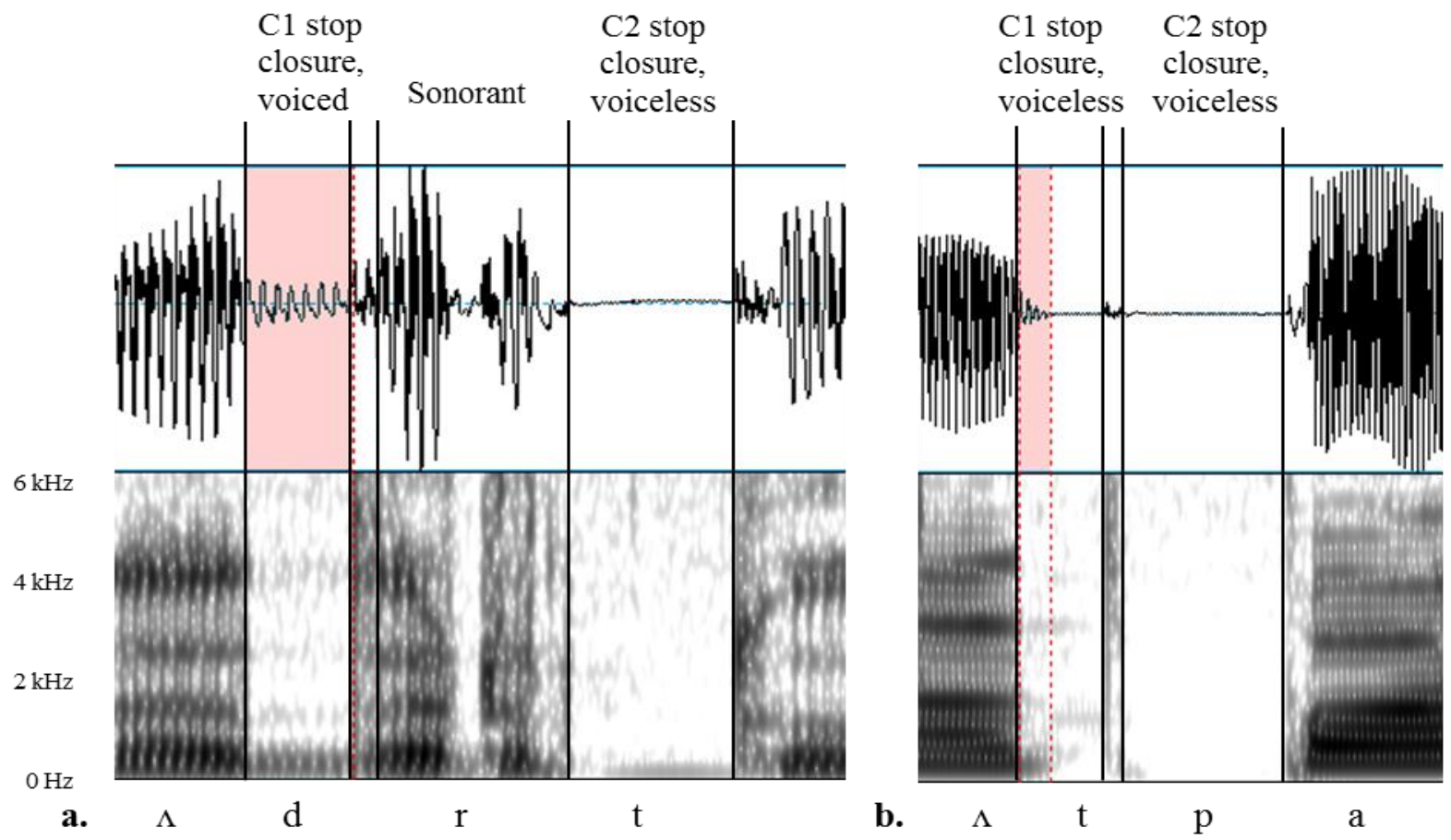

'spacing' and (b) napor[p] 'pressure' (Speaker 2 (male), fast rate). The voiced part of closure/frication is highlighted.

Figure 2.Examples of acoustic measurements in target obstruents in clusters: (a) contrastive Sonorant+Obstruent environmentnad[d]rtutju 'over mercury', spoken by Speaker $10(\mathrm{~m})$, fast rate (fully voiced C1 stop closure, voiceless $\mathrm{C} 2$ closure) and (b) assimilating Obstruent environment: nad[t]parom 'over steam', spoken by Speaker 1 (female), fast rate (voiceless $\mathrm{C} 1$ stop closure, voiceless $\mathrm{C} 2$ closure). The voiced part of stop closure is highlighted. 

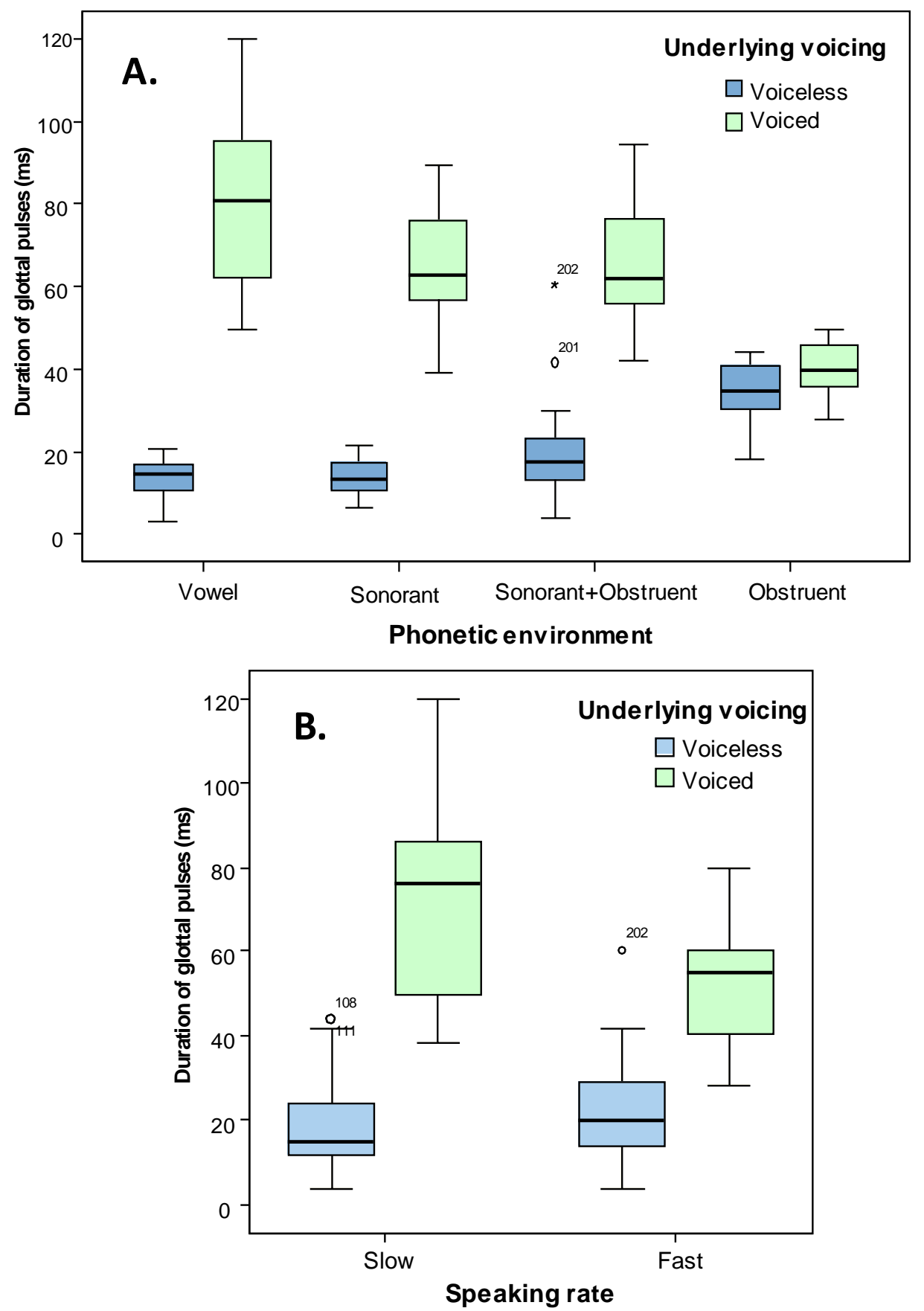

Figure 3.Boxplots of voicing durationsin underlying voiced and voiceless target obstruentsin (A) four phonetic environments and (B) at two speaking rates. 


\section{A. Voiceless}

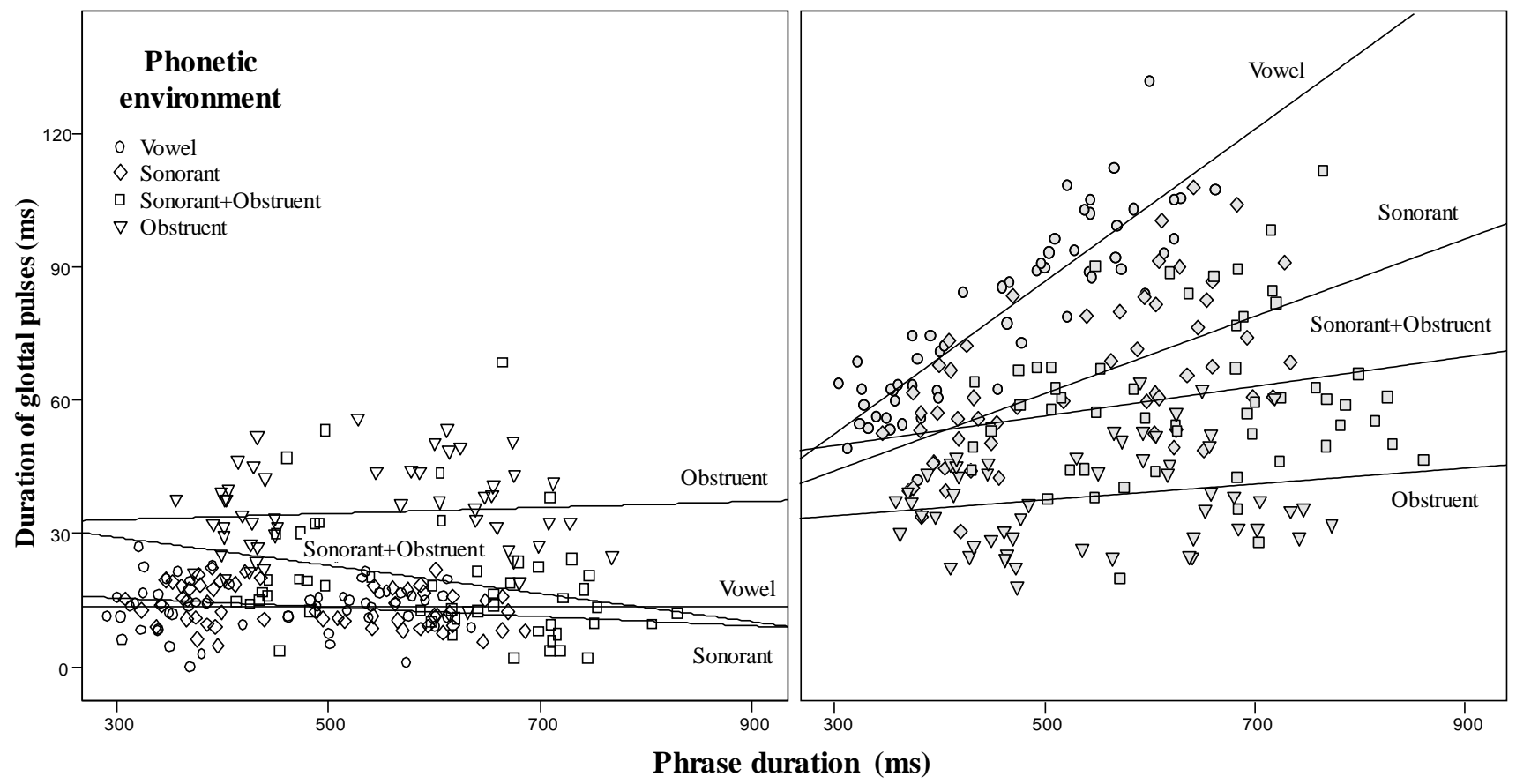

Figure 4.Changes in duration of glottal pulses inunderlyingly voiceless and voiced target obstruents as a function of phrase duration and phonetic environment. 